\title{
Franquismo y exportación cultural. El papel de "lo español" en el apadrinamiento de la vanguardia
}

\author{
Alicia Fuentes VegA \\ Universidad Complutense de Madrid, Facultad de geografía e historia, Dpto. Historia del Arte III \\ (Becaria FPU). Proyecto de Investigación I+D "Los lugares del arte. Del taller del artista al espacio \\ expandido en la sala de exposición".
}

\begin{abstract}
RESUMEN
Es un hecho ampliamente reconocido que durante los años 50 y 60 el régimen franquista hizo un movimiento de acercamiento a la vanguardia, en aras de conseguir la necesaria modernización y apertura del país. Una vez que se ha incorporado dicho apadrinamiento de la vanguardia al discurso historiográfico del franquismo, hay que plantearse la posible presencia de estereotipos en la versión canónica del relato. Este artículo, como aportación a tal relectura, se centra en un punto de vista concreto: el de "lo español".
\end{abstract}

Palabras clave: Franquismo; apertura; instrumentalización de la vanguardia; "lo español”.

\section{Franco's cultural exports. The role of "the spanishness" in the manipulation of the avant-garde}

\begin{abstract}
It is widely recognized that the Franco regime tried to approach the avant-garde during the $1950 \mathrm{~s}$ and $60 \mathrm{~s}$ in order to achieve the country's necessary modernization and liberalization. Once we have introduced this manipulation of the avant-garde by the Franco regime in our historiographical discourse, we may think about the possibility that there are some stereotypes within that version of the story. This article intends to contribute to that kind of re-reading by studying the matter from the specific point of view of "the spanishness".
\end{abstract}

Keywords: Franco regime; policy of openness; exploitation of the avant-garde; "the spanishness".

${ }^{1}$ Al revisar la actividad de la Dirección General de Relaciones Culturales desde el final de la II Guerra Mundial, nos encontramos con tres exposiciones que se consideran hitos importantes porque marcan el comienzo de un apadrinamiento de la vanguardia por parte del franquismo:

1 Este artículo recoge algunos resultados de mi investigación-DEA, presentado en septiembre 2009 y elaborado bajo la tutoría de la Dra. Estrella de Diego, mientras era beneficiaria de una beca de iniciación a la investigación de la UCM. 
- La celebrada en Buenos Aires en 1947, que ha sido señalada como el primer intento del régimen de mostrar un arte moderno en el exterior,

- la exposición de arte español de El Cairo en 1950, que viene considerándose el paso siguiente a la anterior porque el régimen expuso por primera vez a Picasso,

- y la Bienal de Venecia de 1952, en la que se presentaron obras de artistas más jóvenes, como Tàpies o Guinovart, acercándose ya a la denominada "era González Robles", es decir; al momento triunfal del informalismo como representante del Estado español en el exterior.

Se trata de exposiciones míticas para la historia del arte del franquismo, que son paradigmáticas del progresivo acercamiento del régimen al arte moderno. Exposiciones, por tanto, cargadas de significado histórico. Quizá por ello, han cristalizado en torno a ellas una serie de estereotipos historiográficos que las reducen a ser sólo eso: símbolo del apadrinamiento de la vanguardia, omitiéndose toda revisión que pudiera sacar a la luz nuevos datos o apreciaciones que matizasen nuestra comprensión de tal fenómeno.

En lugar de centrarme en una de estas exposiciones, quiero hablar aquí de las principales conclusiones que se pueden extraer del estudio de todas ellas en conjunto, aunque trataré de demostrar mis afirmaciones con ejemplos prácticos concretos.

\section{No sólo Tàpies}

Al repasar la abundante literatura existente sobre el tema de arte moderno y franquismo, se perfilan pronto unos ejes geográficos y cronológicos que delimitan el proceso de apadrinamiento de la vanguardia. Generalmente se pone el principio de dicho proceso en la I Bienal Hispanoamericana de Arte celebrada en Madrid en 1951, que ha sido ampliamente estudiada por Miguel Cabañas $\mathrm{Bravo}^{2}$; y se considera como desenlace final la exportación definitiva de la plástica informalista, que se vio claramente en la Bienal de Venecia de 1958 y continuó durante los años 60. Pues bien, la primera idea que quiero resaltar es la de que la asimilación de la vanguardia no responde a momentos aislados, como serían la I Bienal Hispanoamericana o la de Venecia del 58, ni tampoco a un único movimiento artístico, como sería el informalismo. Todo lo contrario, se trata de un fenómeno que podríamos considerar una constante dentro de la política cultural del franquismo, y que podemos rastrear hasta bastante atrás en el tiempo.

2 CABAÑAS BRAVO, Miguel, Política artística del franquismo. El hito de la Bienal Hispanoamericana de Arte, Madrid, CSIC, 1996. 
En un momento tan temprano como 1947, por ejemplo, se llevaron a la exposición de arte español contemporáneo de Buenos Aires auténticas muestras de arte joven, algunas muy en consonancia con las tendencias internacionales. Concretamente, en la selección de Buenos Aires estaba abundantemente representada la "Joven Escuela Madrileña" (con obras de Luis García-Ochoa, Agustín Redondela, Menchu Gal, Álvaro Delgado, Rafael Zabaleta y Eduardo Vicente, entre otros), así como el grupo de los Indalianos, entre ellos Jesús de Perceval, Francisco Capuleto y Luis Cañadas. Pero no son éstos los únicos artistas de vanguardia incluidos en Buenos Aires. Cuando se repasa el catálogo, sorprende encontrarse con un buen número de figuras plenamente vinculadas a las vanguardias históricas de preguerra, cuya trayectoria parece de sobra conocida a la intelectualidad franquista. Leemos una pormenorizada biografía de María Blanchard, mencionando sus contactos con Picasso y Juan Gris; un detallado repaso de la evolución de Pablo Gargallo que hace hincapié en su etapa parisina; o un relato de la vida de Salvador Dalí que no oculta sus inicios surrealistas ni sus colaboraciones cinematográficas con Buñuel. ${ }^{3}$ Se incluye también a figuras inequívocamente relacionadas con posturas políticas de izquierdas e incluso vinculadas de forma explícita a la II República. Tal es el caso de Ángel Ferrant-cuya pertenencia a grupos renovadores de preguerra como Amics de l'Art Nou, Els Evolucionistes o el Salón de Artistas Ibéricos no sólo no es ocultada sino que se menciona explícitamente-, el caso de Benjamín Palencia y también el de artistas en el exilio como Gregorio Prieto. ${ }^{4}$

Tradicionalmente se ha dicho que el franquismo, sobre todo en los primeros años, demonizó la vanguardia, interpretando el cubismo y el surrealismo como demostración de la degeneración de la civilización occidental. Sin embargo, aquí tenemos que en un momento tan temprano como 1947, tales movimientos son conocidos y aceptados sin reparos, citados sin ambages y con nombre propio; son reivindicados, en suma, como valores objetivos que dotan a aquellos artistas españoles que participaron en ellos -y al Estado español en general- de legitimidad internacional.

Otro grupo que se incluye en la exposición para fomentar esa idea de cosmopolitismo es -gran sorpresa- una serie de mujeres pintoras. Pilar Muñoz López ha llamado la atención sobre la inusitada cantidad de mujeres que fueron incluidas en la selección de Buenos Aires, y ha encontrado la razón de esta nutrida representación femenina en el intento por parte del Estado español de "mostrar una pintura figurativa con influencias y maneras más cercanas a la modernidad". ${ }^{5}$ Son pintoras como $\mathrm{M}^{\mathrm{a}}$ del Carmen Álvarez de Sotomayor y Marisa Röesset y Velasco, hija y discípula, respectivamente, de Fernando Álvarez de Sotomayor, director del Museo

3 Exposición de arte español contemporáneo. Pintura y escultura, catálogo de exposición (Buenos Aires, 1947), Madrid, Dirección General de Relaciones Culturales, 1947, pp. 24, 31 y 92.

4 Ibid., pp. 57, 60, 90.

5 LÓPEZ, Pilar, "Mujeres en la producción artística del siglo XX", en Cuadernos de Historia Contemporánea (UCM), nº 28, 2006, pp. 97-117. 
del Prado y además co-comisario de la exposición. Algunas de estas pintoras serían incluidas, por tanto, tan sólo en virtud de hijas o discípulas de. Sin embargo, no cabe duda de que otras merecerían ser incluidas por su propia calidad y cosmopolitismo. Entre ellas, el caso que más salta a la vista es el de María Blanchard, pero también sería el de Teresa Condeminas -que destaca por haber sido la única artista española que cultivó el género del desnudo, inaceptable en una mujer-. Este sería el caso también de Delhy Tejero y Menchu Gal, ambas vinculadas a la Escuela de Madrid y a la vanguardia internacional; o el de Rosario de Velasco, la cual había desempeñado, de nuevo en palabras de Pilar Muñoz, "un papel destacado en el mundo artístico anterior a la guerra civil"'

Por todo esto, podemos concluir que en la exposición de arte español en Buenos Aires, cuatro años antes de la I Bienal Hispanoamericana, ya se hizo patente un claro intento de las instituciones franquistas por presentar un arte español con valores cosmopolitas, renovadores e incluso relacionados con las vanguardias históricas y el ambiente español de preguerra. Hay que insistir en la idea de que, si bien cuando hablamos de instrumentalización de la vanguardia por parte del franquismo pensamos inmediatamente en el caso de los informalistas, antes que ellos corrió esa misma suerte una larga nómina de artistas. Entre quienes suscriben esta visión está Jordi Gracia, quien afirma que, "Si es entre los jóvenes núcleos abstractos e incipientemente informalistas donde más vistosa y afortunada -para ambas partes-resultó la cooperación con el Estado", ésta también consistió en la "inmediata oficialización de Vázquez Díaz, Benjamín Palencia, o, en el caso más revelador de todos, José Gutiérrez Solana"7. Gabriel Ureña, que también ha tratado bastante este tema, opina además que se hizo toda una "recuperación" de la pintura anterior -desde Fortuny hasta Sorolla, Ramón Casas, Pinazo o Nonell-, recurriéndose, para recuperar conjuntamente a pintores tan diversos, a su común raigambre nacional. ${ }^{8}$ De hecho, podríamos retrotraer la estrategia de apropiación de la modernidad incluso hasta el 98. El espíritu inequívocamente liberal de tipo regeneracionista de los autores del 98 no supuso obstáculo alguno para que éstos fueran rápidamente recuperados por la intelectualidad falangista, idea que ha sido estudiada por $\mathrm{M}^{\mathrm{a}}$ Isabel Cabrera García9 .

Así pues, hay bastantes artistas a los que el régimen dirigió su mirada, ya desde la primera posguerra, con la finalidad de dotarse de un barniz de modernidad cultural. Si bien la mayoría no suponían ni mucho menos la vanguardia del momento, como es

6 Ibid., p. 12.

7 GRACIA, Jordi, Estado y cultura. El despertar de una conciencia crítica bajo el franquismo (19401962), Barcelona, Anagrama, 2006, p. 46.

8 UREÑA PORTERO, Gabriel, "La nueva pintura de la España Eterna", en BONET CORREA, Antonio (coord.), Arte del franquismo, Madrid, Cátedra, 1981, pp.159-205.

9 CABRERA GARCÍA, Ma Isabel, Tradición y vanguardia en el pensamiento artístico español (19391959), Granada, Universidad de Granada, 1998, p. 20. Según esta autora, el régimen encontró "conexiones con el discurso teórico noventayochista" por sus valores casticistas, tradicionalistas y nacionalistas. 
el caso de los noventayochistas o de Solana, no se puede negar que sí representaban un considerable grado de modernidad, de modo que las instituciones franquistas tratarían de servirse de ellos con la misma finalidad que más tarde les llevaría a utilizar a los informalistas. Sin embargo, muy a menudo se ha atendido sólo a la presencia o no de estos últimos para dictaminar si en las exposiciones se daba ese intento de modernización. Quizá haya sido una fijación exclusivista de nuestros historiadores con la estética de la gestualidad, la que ha llevado a otorgar ese protagonismo a la I Bienal Hispanoamericana y a las exposiciones de la era González Robles como paradigmas de la unión de franquismo y vanguardia. La pintura gestual era el símbolo de la modernidad en la época de formación de aquellos historiadores que madurarán durante los años 70 , por lo que es lógico que acaparara todas sus atenciones. Pero para comprender en todo su alcance el origen de dicha fijación exclusivista, propongo que dirijamos nuestra atención al tema de "lo español".

\section{"Lo español": El argumento definitivo}

Si las instituciones culturales franquistas querían actualizar su imagen, primero tenían que fabricar un discurso de modernidad propia que fuera creíble y, sobre todo, aceptable para los propios medios internos conservadores. Esta necesidad va a originar un aparato interpretativo que consistirá en encontrar, en todos los artistas de vanguardia que se deseen asimilar, inequívocas señas de españolidad.

Se trata de la solución de la llamada "tercera vía", que ha sido identificada por Ángel Llorente y Julián Díaz Sánchez como aquello que permitió salvar el aparentemente insalvable escalón entre modernidad y franquismo. Promovida por críticos como Enrique Azcoaga y Lafuente Ferrari desde principios de los años 40, la tercera vía abrió, según los autores mencionados, "la posibilidad de utilizar un lenguaje moderno, pero en ningún caso vanguardista" $"$. Se buscaba un arte que, si bien introducía novedades plásticas de tipo internacional que lo acercaban peligrosamente a la vanguardia, ahuyentaba toda suspicacia por el hecho de ser plenamente "español". Es decir; un arte moderno, pero propio. Hecha esta salvedad, cualquier innovación plástica sería aceptable para el franquismo de la apertura.

La idea de lo español va a ser, por tanto, el verdadero vehículo que haga posible la operación de apadrinamiento de la vanguardia. De entre quienes han estudiado este tema, Julián Díaz Sánchez es uno de los historiadores que más claramente ha señalado la importancia de "lo español" en el caso concreto de la instrumentalización del informalismo, llegando a la conclusión de que el triunfo de este tipo de pintura "se basó, fundamentalmente, en la posibilidad de encontrar en esta tenden-

${ }^{10}$ LLORENTE HERNÁNDEZ, Ángel, "Panorama de la crítica de arte en la posguerra (1939-1951)", en DÍAZ SÁNCHEZ, Julián y LLORENTE HERNÁNDEZ, Ángel, La crítica de arte en España (1939-1976), Madrid, Istmo, 2004, p. 26. 
cia, con más facilidad que en otras, unas raíces españolas"11. Esa identificación con lo español la fomentaban los propios autores informalistas con sus referencias explícitas a la tradición pictórica hispánica (es de sobra conocida, por ejemplo, la obsesión de Saura con Goya), pero también se encontraba en categorías más abstractas como la de lo dramático, lo espiritual, lo negro o la potencia masculina. Sin embargo, lejos de ser únicamente "español", el informalismo se inscribía dentro de las tendencias más internacionales del momento. Concretamente, seguía los pasos del expresionismo abstracto norteamericano que durante los años 50 y 60 se impuso en toda Europa, pudiendo hablarse de una auténtica "globalización estética"12.

Sea lícito o no interpretar la pintura informalista como netamente española, se debe reconocer que fue principalmente esa supuesta presencia de señas hispanas lo que la hizo más popular a ojos no sólo del franquismo, sino también de la crítica de arte posterior, pues al ser tan inconfundiblemente español, el informalismo era el producto más adecuado para la efectiva y contundente exportación cultural que necesitaba lanzar la España de la transición. Sin embargo, debería llamarnos la atención que habiendo sido el argumento de "lo propio" un claro instrumento ideológico del franquismo, la historiografía posterior, aquella escrita en plena democracia, siguiera empeñada en encontrar señas de españolidad en la pintura informalista o en cualquier otra vanguardia producida en España. Tal continuación de los discursos franquistas en democracia es algo que debe ser puesto en evidencia, y que de hecho constituye una preocupación actual de la historia del arte ${ }^{13}$.

En cualquier caso hemos visto que los informalistas no son, ni mucho menos, los únicos artistas a los que se aplica el discurso de "lo moderno, pero propio". Más bien al contrario, éste había sido una constante en la crítica y en el discurso oficial desde el principio de la posguerra. Lo encontramos, sin ir más lejos, en el caso de Solana, quien acaparó el protagonismo en la exposición de Buenos Aires de 1947. Su obra obtuvo un gran éxito de crítica y fue la que concentró el mayor número de adquisiciones ${ }^{14}$. Se

11 DÍAZ SÁNCHEZ, Julián, "Perfiles de la crítica (1951-1976)", en ibid., p. 78. Según este mismo autor, fue la presencia de esas señas españolas la que hizo que el informalismo triunfase sobre la abstracción geométrica cultivada por Equipo 57, siendo éste "menos manipulable ideológicamente, y, desde luego, menos españolizable" que El Paso (ibid., p. 86).

12 La tesis del pintor informalista Salvador Victoria es bastante esclarecedora acerca del verdadero origen internacional del informalismo, pues deja constancia de que la fuente de inspiración de la que bebieron todos estos artistas fue la gran cantidad de exposiciones de expresionismo abstracto norteamericano que se pudieron ver durante los años 50 y 60 en París, donde muchos de ellos residían. VICTORIA, Salvador, El informalismo español fuera de España, Zaragoza, Ibercaja, 2001.

13 Tal es el caso de autores como Jorge Luis Marzo, quien declara que sus "intenciones, guiadas por una sospecha largamente razonada, se encaminaban a demostrar el continuismo de las políticas artísticas desarrolladas en España - tanto en la dictadura, en la transición como en democracia-." MARZO, Jorge Luis, Art Modern i Franquisme: els orígens conservadors de l'avantguarda i de la política artística a l'estat espanyol, Girona, Fundació Espais d'Art Contemporani, 2007, p.175.

14 SÁNCHEZ-CAMARGO, Manuel, "La exposición de arte español en Hispanoamérica", en Mundo Hispánico, $\mathrm{n}^{\circ} 1,1948$, p. 46. 
expuso, entre otros lienzos, su famosa Tertulia del café de Pombo, sobre el cual Gómez de la Serna, afincado por entonces en la capital argentina, dictó una conferencia que fue muy publicitada en la prensa ${ }^{15}$. Esta obra, por cierto, había sido precisamente donada por él mismo tan sólo un mes antes al Museo Nacional de Arte Moderno de Madrid ${ }^{16}$. Eduardo Llosent, comisario de la exposición de Buenos Aires pero también director de dicho museo, la enviaría nada más recibirla a ocupar un puesto de honor en la muestra bonaerense, antes incluso de que los propios madrileños pudieran contemplarlo en las salas de su museo. Esto debe hacernos reflexionar sobre el hecho de que se priorizase el mostrar a Solana hacia el exterior antes que al interior.

Pero lo que ahora nos interesa es el tipo de interpretación que se hizo de la obra de Solana. A tal efecto es muy representativo el artículo que publicó en Cuadernos Hispanoamericanos Juan Zocchi, director del Museo de Bellas Artes de Buenos Aires que albergó la exposición. Sus palabras sobre Solana fueron éstas:

“... advierto que lo que Gutiérrez Solana ha pintado y ha dicho, después de otros españoles que lo han pintado y lo han dicho en modos distintos, por ejemplo Zurbarán, el Greco, Goya, Calderón, Unamuno, es esencia de lo español, y que la particular actitud de Gutiérrez Solana es la actitud del ser español. Nadie, nadie en nuestro mundo occidental por lo menos, siente y se hace cargo de la devoradora realidad como el hombre español. $Y$ he aquí por qué el sentimiento y la conciencia que éste tiene de la vida es en definitiva una conciencia y un sentimiento de juicio final." 17

Hay aquí toda una evocación romántica sobre "lo español" en base a los más típicos clichés sobre lo ibérico, como el del mito de la diferencialidad o el de la espiritualidad, el dramatismo y el apasionamiento. Esto explica el éxito de Solana en la exposición bonaerense: en los artistas académicos como Álvarez de Sotomayor sólo se vería un realismo más o menos estéril, y en la vanguardia cosmopolita de influencia cubistizante o surrealizante se perdería algo de la tradición española - por ejemplo, llama la atención lo poco que se habló de la participación de una figura tan conocida como Dalí. Sin embargo, en Solana se aseguraban ambas cosas a la vez: una celebración de los valores hispanos tradicionales, pero también una innegable modernidad estética de tipo expresionista. Esto es; la solución de lo moderno, pero propio. Que Solana, republicano confeso, fuera "tan bien tratado desde las altas esferas de la oficialidad artística" es calificado de "misterio" por Rosalía Torrent ${ }^{18}$. Sin embargo, el misterio es fácilmente descifrable. La pintura de Solana es dramática, en ella predomina lo negro y además retrata tradiciones y tipos populares. No podía ser, en fin, más española.

15 "Conferencia de Ramón en la Exposición de Arte Español en Buenos Aires", en Arriba, 31/10/1947, p. 6.

${ }^{16}$ El 18 de junio de 1947. Vid. JIMÉNEZ-BLANCO, Ma Dolores, Aportaciones a la historia de los fondos del Museo Español de Arte Contemporáneo (tesis doctoral), Madrid, UCM, 1988, p. 724.

17 ZOCCHI, Juan, "La exposición del Arte Español Contemporáneo en Buenos Aires", en Cuadernos Hispanoamericanos, $\mathrm{n}^{\circ}$ 2, 1948, pp. 301-310.

18 TORRENT, Rosalia, Un siglo de arte español en el exterior. España en la Bienal de Venecia 18952003, Madrid, Ministerio de AA. EE. - Dir. Gral. de Relaciones Culturales y Científicas, 2003, p. 45. 
Precisamente ahí está la clave de la fabulosa efectividad del argumento de "lo moderno, pero propio": mediante lo español, se vacía de todo contenido ideológico la obra de arte. Una despolitización más que necesaria si el régimen quería asimilar como propias figuras tan reconocidas internacionalmente $-\mathrm{y}$ por tanto tan golosas - como Picasso. La razón última que lleva a echar mano de lo español en la interpretación del arte moderno es, sin duda, la necesidad de desideologizarlo. Cosa que se consigue fácilmente reduciéndolo a señas nacionales. Así pues, no debemos subestimar la tremenda potencialidad del argumento de "lo español" como estrategia instrumentalizadora de la cultura por parte del Estado.

\section{Una historia discontinua}

He comenzado mi exposición hablando de la cristalización de estereotipos historiográficos en torno al tema del apadrinamiento de la vanguardia por el régimen. Pues bien, otro de esos estereotipos es el de la linealidad. Partiendo de la idea de que hay un punto culminante que necesariamente va a ser el apadrinamiento del informalismo, se leen todas las exposiciones anteriores como pasos sucesivos y progresivos conducentes a ese desenlace final. Sin embargo, los hechos no siempre se corresponden de forma exacta con ese relato lineal.

En su proceso de modernización cultural el régimen tomará como ensayos clíni$\cos$ las ocasiones que se le brinden de mostrarse al exterior, de modo que podríamos hablar de un tanteo, un ir probando. La Dirección General de Relaciones Culturales probará diferentes puestas en escena en las diversas exposiciones que organice durante estos años, pudiendo reconocerse altibajos, avances y retrocesos en el proceso. Concretamente se llega a planteamientos bastante modernos en momentos tempranos que sin embargo luego vienen seguidos de una regresión. Esto ocurre, por ejemplo, al comparar la exposición de Buenos Aires de 1947 con la de El Cairo en 1950, la cual bien podría ser considerada un paso atrás respecto de la anterior. Sin embargo, el papel que se le viene otorgando al certamen cairota es el de un acercamiento a la vanguardia. Este es uno de los estereotipos historiográficos que más me ha llamado la atención de los relacionados con este grupo de exposiciones. Veamos por qué.

En la introducción del catálogo de la exposición de El Cairo, escrita por el Director General de Relaciones Culturales, Carlos Cañal, éste afirma que el propósito de dicha muestra era claramente enseñar el arte "de hoy" 19 . Sin embargo, en el texto inmediatamente siguiente se amplía el alcance de la misma al arte "desde Goya a nuestros días" ${ }^{20}$. Así, sin más explicaciones, el espectador ha pasado de estar a pun-

19 CAÑAL, Carlos, Exposición de Arte español en El Cairo, catálogo de Exposición (El Cairo, 1950), Madrid, Dirección General de Relaciones Culturales, 1950, pp. 21-22.

20 "Prefacio" (anónimo), en ibid., pp. 25-32. Podemos suponer que el autor sería Pérez Comendador, como comisario principal de la muestra, pero también se ha apuntado a la posibilidad de que fuese Lafuente Ferrari (vid. TUSELL, Javier, "El ambiente cultural, político y artístico en el Madrid de posguerra", en 
to de ver una exposición de arte decididamente contemporáneo, a otra mucho más laxa en su contenido real de modernidad, pues se han ensanchado extremadamente los límites temporales. Desde Goya hasta nuestros días hay, en efecto, un gran hueco: todo el siglo XIX.

Si tuviéramos que resumir en una sola palabra la exposición de El Cairo de 1950, ésta sería sin duda "decimonónica". Por el contrario, lo que generalmente más se ha resaltado de ella ha sido la inclusión de algunos artistas vanguardistas; y más concretamente el hecho de que ya se expusieran dos lienzos de Picasso. Esto originó la famosa frase de perdón oficial que se puede leer en la introducción del catálogo -por ser un "malagueño universal, que, a pesar de sus disidencias, por tantos rasgos de su arte desdeñoso e imprevisible, sigue siendo profundamente español" 21 . Sin embargo, no debemos dejarnos cegar por el hecho, más o menos aislado, de que por primera vez el franquismo expusiera a Picasso, ni tampoco por que hubiera también algunos lienzos de Dalí -el cual ya había vuelto a España, siendo plenamente aceptado por los círculos franquistas. Si no nos dejamos cegar por esos hechos aislados, como digo, nos daremos cuenta de que el mayor protagonismo en El Cairo se lo llevaron los artistas más ligados a la tradición realista del XIX y al regionalismo de principios de siglo (fig. 1).

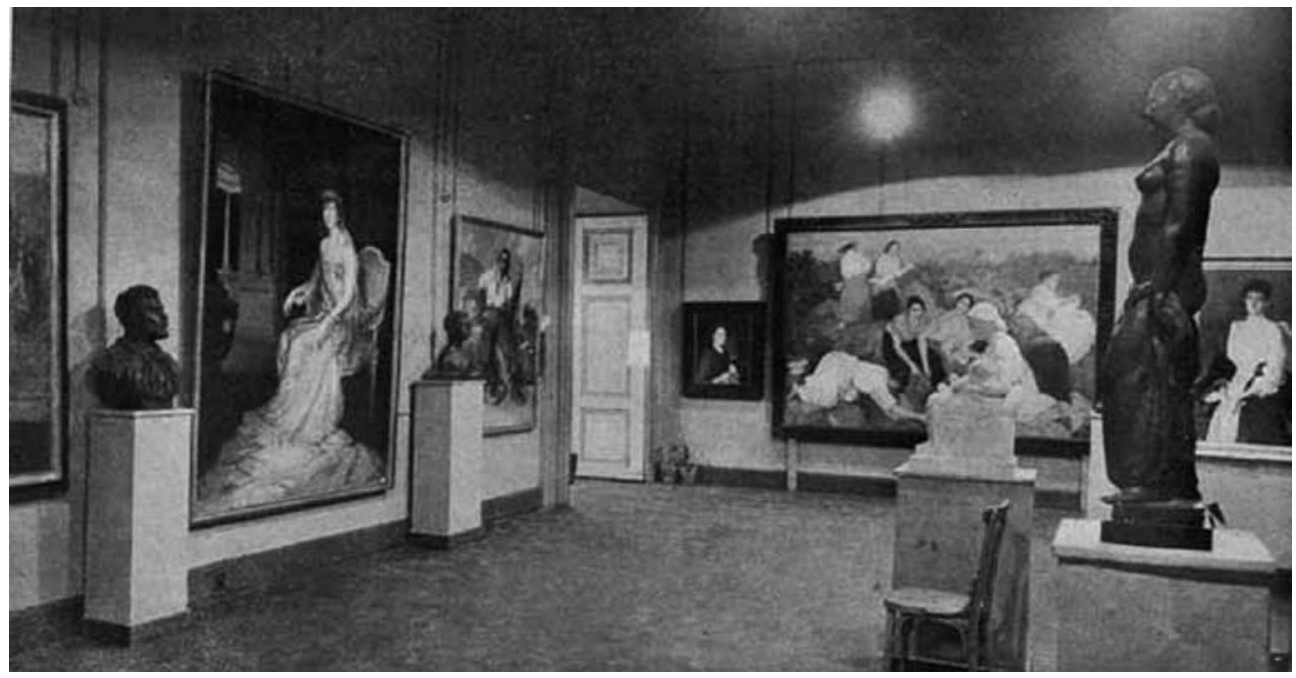

Fig. 1. Una de las salas de la Exposición de arte español de El Cairo, en la que se ven obras de Benlliure, Eugenio Hermoso y Álvarez de Sotomayor, entre otros. El conjunto da idea del tono conservador de la exposición. [fotografía tomada de: PÉREZ COMENDADOR, Eugenio, “Arte español en Egipto”, en Arte español, Madrid, 1950 (pp. 108-112)].

TUSELL, Javier y MARTÍNEZ-NOVILLO, Álvaro, Arte para después de una guerra, Comunidad de Madrid y Caja de Madrid, 1994, p. 41.

21 "Prefacio" (1950), op. cit., p. 30. 
No queda duda de esto al comparar el catálogo de El Cairo con el de la exposición de Buenos Aires de 1947, pues la primera diferencia que salta a la vista es esa mayor presencia del siglo XIX. Ahora se incluye un buen número de artistas nacidos en torno a los años 40 del ochocientos (como Muñoz Degrain, Ignacio Pinazo, Agustín Riancho, Aureliano Beruete, Eduardo Rosales; o incluso Madrazo y Eugenio Lucas, nacidos en los años 10), ninguno de los cuales estuvo en Buenos Aires, donde la generación más vieja había sido la nacida en torno a la década de los 70. Además, muchos de los artistas más jóvenes que se habían mostrado en Argentina ahora desaparecen. Repiten Luis García-Ochoa, Álvaro Delgado, Pedro Bueno, Francisco Arias, Rafael Zabaleta, Juan Antonio Morales y Eduardo Vicente, así como otros artistas renovadores como José Amat o Rafael Durancamps; pero se quedan fuera Menchu Gal, Agustín Redondela, Antonio Lago, Pablo Palazuelo, y los Indalianos Perceval, Capuleto y Cañadas.

Por tanto no es del todo cierta la imagen que dibuja, entre otros, Javier Tusell de una exposición ya decididamente moderna. Se supone que en El Cairo el peso de la tradición -Zuloaga, Álvarez de Sotomayor-sería ya escaso, frente a una presencia mayor del surrealismo -Dalí, Eduardo Vicente, Caballero ${ }^{22}$. Pero, si bien esos artistas renovadores estuvieron presentes, no fue en calidad de representantes del surrealismo, ni mucho menos, ni tampoco fueron los protagonistas de la muestra. Si generalmente se ha interpretado la exposición de El Cairo como un paso adelante en la modernización de las estructuras oficiales, ha sido dejándose llevar, por un lado, por la poderosa carga simbólica de la figura de Picasso; y, por otro, por empeñarse en presentar el proceso de asimilación estatal de la vanguardia como algo progresivo, consistente en un avance lineal y unidireccional que por fuerza habrá de estar marcado por hitos -las diversas exposiciones en el exterior-consecutivos -más modernas cada vez.

Analizando la inclusión de Picasso y Dalí desde otro punto de vista, podremos comprender el conjunto de la estrategia que se puso en práctica en la exposición de El Cairo: se continúa exhibiendo a los mismos artistas de siempre -Sotomayor, Aguiar, Zuloaga, Zubiaurre, Benedito, Chicharro, Hermoso-; a estos se les añade una abundante representación del siglo XIX -Rosales, Madrazo, Eugenio Lucas, Pinazo, Muñoz Degrain, Benlliure-; y luego se intenta legitimar el conjunto revistiéndolo de algo de modernidad, por medio de un par de figuras vanguardistas de renombre mundial: Dalí y Picasso. Estos son incluidos tan sólo como iconos; no por lo que suponen de renovación artística sino por ser figuras altamente reconocidas, que de forma inmediata dotarán a la exposición de respetabilidad de cara al panorama internacional. No es difícil darse cuenta de que en estos apadrinamientos había bien poco de compromiso estético o moral. Se quieren los nombres, los iconos culturales, pero no necesariamente lo que éstos

\footnotetext{
22 TUSELL, Javier (1994), op. cit., p. 41.
} 
conllevan de modernidad: se quiere el significante pero no el significado. Por eso se escogen artistas mediáticos y fácilmente vaciables de contenido ideológico, que son reducidos a mera marca.

La ficha de Picasso en el catálogo de la muestra egipcia es un ejemplo claro de esa despolitización. En ella se analiza su trayectoria artística reduciéndola a categorías y clasificaciones (los típicos "época azul”, "época rosa", "época clásica”) que funcionan como denominaciones de origen y limitan el análisis a los aspectos formales, evitando toda interpretación estética o ideológica más de fondo. Se añade de nuevo el famoso perdón por conservar, pese a todo comunismo, "rasgos esencialmente españoles" ${ }^{\text {"23 }}$, y se eligen dos cuadros relativamente clasicistas -el Arlequín de 1917 del Museo de Barcelona, de composición más o menos cubistizante pero absolutamente figurativo en su concepción, y una Naturaleza muerta de 1901 del mismo museo. Y ya tenemos la asimilación completa.

Otro caso de ese tipo de estrategia lo encontramos en la Bienal de Venecia de 1950, la anterior a la que en 1952 organizará Lafuente Ferrari incluyendo ya a los informalistas Tàpies y Guinovart. El talante conservador de la participación española de 1950, por el contrario, quedaba garantizado por el hecho de que su comisario fuera el muy antivanguardista Enrique Pérez Comendador, quien también había sido responsable de la de El Cairo ese mismo año. Consciente del atraso de una selección española cuyo plato fuerte debía ser la saga de los Madrazo-Fortuny, en su texto del catálogo Carlos Cañal, Director General de Relaciones Culturales, presentó una historia del arte español marcada, de forma algo inconexa, por las figuras de Ribera, Zurbarán y Velázquez, después Goya, para pasar luego a Zuloaga, Sert y Solana, y terminar con Juan Gris ${ }^{24}$. Sorprende la referencia a este último, que no había sido rescatado todavía por el Estado en ninguna exposición oficial. Pero no se trataba aquí de un rescate ni de una valoración real, sino más bien de un intentar adaptarse a las circunstancias, pues ese año el pabellón internacional de la Bienal le dedicaba una retrospectiva al pintor madrileño, lo cual obligaba a España a reconocer, al menos, su existencia.

La vacuidad de la supuesta valoración de Gris queda patente al constatar que éste no es incluido en la selección española con obras propias, sino por la vía de la metonimia: a través de un retrato que le hizo Vázquez Díaz "en días de común aprendizaje en París"25. Potente imagen que condensa el método de asimilación de la modernidad por parte del régimen (fig. 2). Se toman figuras de la vanguardia pero no de forma directa, sino previamente procesadas, reinterpretadas y reubicadas, vaciándolas de todo contenido político y reduciéndolas a marcas. En un intento ciertamente patético de reclamar

\footnotetext{
23 Exposición de Arte español en El Cairo (1950), op. cit., p. 62.

${ }^{4}$ CAÑAL, Carlos, "Prólogo", XXV Exposición Bienal de Arte en Venecia. Pabellón español, Catálogo de Exposición (Venecia, 1950), Madrid, Dirección General de Relaciones Culturales, 1950, pp. 5-6.

25 Ibid., p. 6.
} 


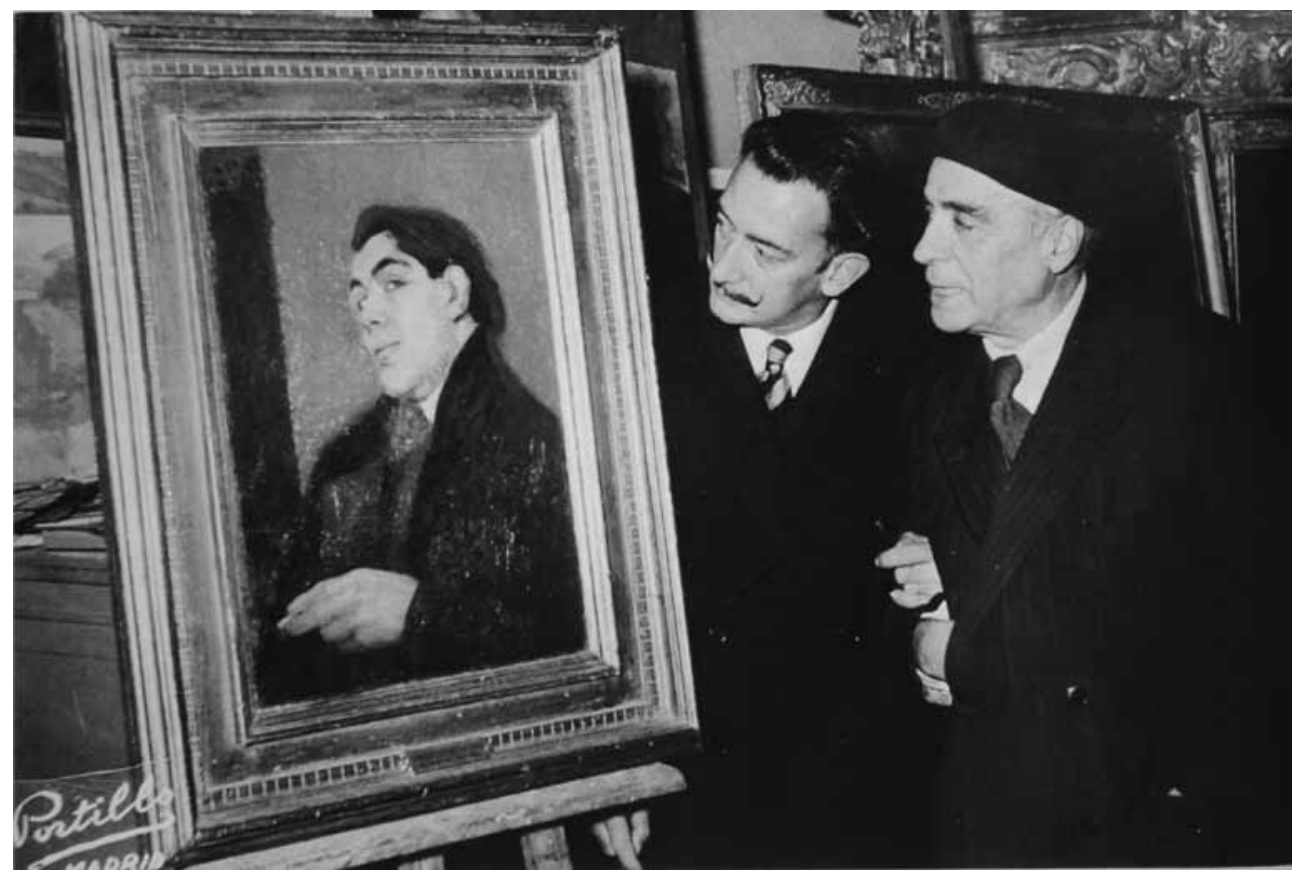

Fig. 2. Salvador Dalí y Vázquez Díaz, ante el retrato de Juan Gris que este último pintó en París en 1908. Madrid, noviembre 1951. [fotografía tomada de: BENITO, Ángel, Vázquez Díaz. Vida y pintura, Madrid, Dirección General de Bellas Artes, 1971, p. 116].

al famoso pintor para España, Carlos Cañal añade además que su "verdadero nombre era González". Esta reivindicación de la figura de Juan Gris por medio de detalles tan anecdóticos como que su apellido fuera González o que fuera retratado por el muy español Vázquez Díaz, es un ejemplo paradigmático del modus operandi del régimen a la hora de reinterpretar la vanguardia para hacer posible su asimilación, sin llegar nunca a comprometerse verdaderamente con ella. Una vez que se ha hecho referencia nominal a figuras de alto reconocimiento internacional como Picasso o Juan Gris, da igual si quien de facto nos representa es Raimundo de Madrazo o Álvarez de Sotomayor.

\section{Los estereotipos nacionales: moneda de cambio}

Volviendo al caso de Solana en Buenos Aires, y al éxito que allí obtuvo, no deja de ser irónico que fuera él quien terminase convirtiéndose en la estrella indiscutible, cuando era Zuloaga quien los organizadores habían dispuesto que fuese el icono de la exposición. Él fue el artista con mayor número de obras en la selección, y además su Retrato del pintor Arango figuraba en la portada del catálogo (fig. 3).

Esto nos habla del último punto que quiero comentar aquí: la existencia de una serie de ideas preconcebidas acerca de lo español en los diversos países a los que se trataba de exportar nuestro arte. En efecto, en Buenos Aires se intentó promo- 


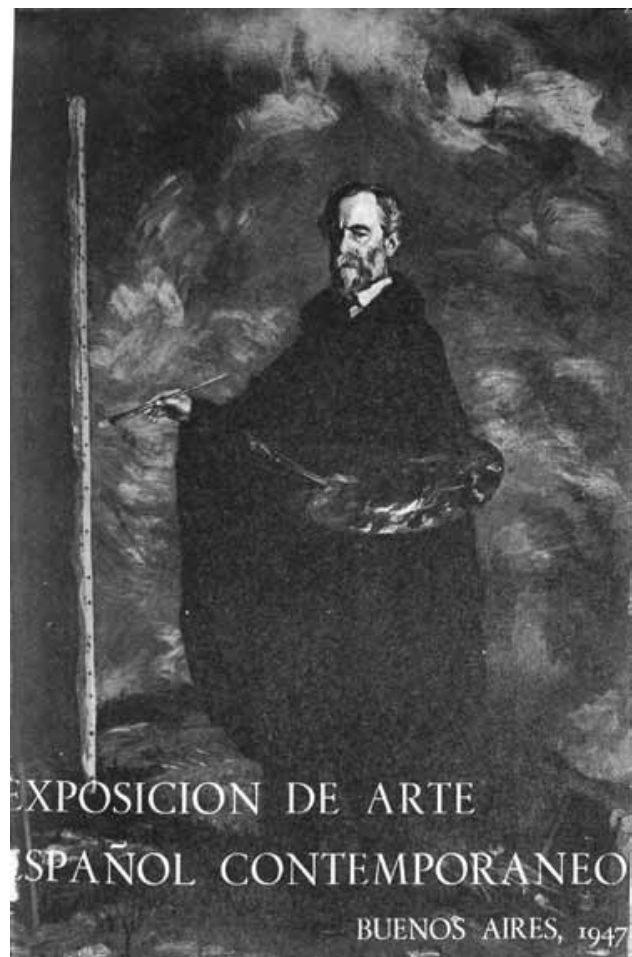

Fig. 3. Portada del catálogo de la Exposición de arte español contemporáneo en Buenos Aires. Madrid, Dirección General de Relaciones Culturales, 1947. Imagen: Ignacio Zuloaga. Retrato del pintor Arango. Óleo sobre tela, 1'62 x 2’20. Colección Zuloaga, Museo de Zumaia.

cionar a Zuloaga, pero sin embargo el protagonismo se lo llevó Solana. De la misma forma, aunque a El Cairo se llevasen obras de Picasso, Dalí y Sorolla, que debían dar una imagen cosmopolita del arte español, en la línea de la modernidad parisina, fue a Goya a quien el público prefirió, pues éste cuadraría mucho mejor con la idea de España que tendrían previamente asumida ${ }^{26}$.

Hay un caso más explícito todavía en el que detectamos la existencia de estereotipos sobre lo español en el extranjero: el de la Bienal de Venecia de 1952. De cara a la Bienal del 50, los organizadores de la misma habían propuesto al gobierno español que en el pabellón de ese año se "presentase una colección de cuadros de Goya y otra de pintores contemporáneos, entre los que debería haber una buena representación de Solana". Así lo ha recogido Ángel Llorente, quien nos cuenta que la idea de la muestra de Goya no cuajó en la Dirección General de Relaciones Culturales, por considerarla, por una parte, demasiado obvia, y por contar, por otra, con las habituales dificultades que impedían la salida del país de obras especialmente importantes. En su lugar, se propuso enviar "una nutrida representación de Solana"27. Cuando llegó la convocatoria de 1952, los responsables del Ente de la Bienal repitieron su solicitud acerca de una exposición de Goya. Ésta, finalmente, se organizó ${ }^{28}$. Pero la

26 Se puede comprobar el éxito de Goya en la muestra de El Cairo a través de la serie de crónicas "Aquí, El Cairo" que el corresponsal del diario Madrid, Luis Climent, escribía cada cierto tiempo sobre la actualidad cairota. Por ejemplo: CLIMENT, Luis, "A la princesa Faiza le ha gustado Goya. Unas declaraciones del Director de Relaciones Culturales", en Madrid, 14/4/1950, p. 5.

27 LLORENTE HERNÁNDEZ, Ángel, Arte e ideología en el franquismo (1936-1951), Madrid, Visor, 1995, p. 136.

${ }^{28}$ La ansiada muestra se formó a base de una serie de cuadros que poseía el Estado (dos de los retratos del Banco de San Carlos, el del conde de Cabarrús y el de José de Toro Zambrano; el retrato de Bayeu del Museo de Valencia; más los pequeños lienzos Fabricación de balas en la Sierra de Tardienta y Fabricación de Pólvora), y uno de colección particular (el retrato de Mariano de Goya). Aunque no aparezcan en el catálogo, hay varios testimonios que añaden tres obras más a esta selección: el Retrato de la Reina María Luisa del Museo napolitano de Capodimonte, y dos cuadritos pertenecientes al Museo francés de Besançon que en su 
insistencia por parte de los organizadores italianos en que España mostrase a Goya debe llamar nuestra atención sobre la evidente existencia de una serie de estereotipos en torno a lo español. Goya era lo propio de España. Por eso, año tras año, lo reclamaban los responsables de la Bienal.

Esto, unido al éxito que en todas las exposiciones obtenían Goya y Solana frente a figuras como Picasso o Dalí, que en principio deberían haber sido más comentadas por el público y la prensa, nos habla de esa predisposición existente en el extranjero a interpretar nuestro arte en clave españolista.

Así pues, en su deseo de modernizar la imagen de España, la Dirección General de Relaciones Culturales chocaría a veces con la predisposición en el extranjero a encuadrar lo español dentro de unos parámetros establecidos. He aquí un obstáculo de cara a la modernización externa del régimen; obstáculo que una vez se haya sabido solucionar dejará de serlo, para convertirse en una muy aprovechable ventaja, pues, como hemos visto, esa existencia de estereotipos sobre lo español se acabará explotando ampliamente y en beneficio propio. De modo que la cuestión de la identidad nacional no es otra cosa que moneda de cambio dentro de la dinámica de las relaciones exteriores.

Si me presento al otro de una forma en que nunca me ha visto, no me va a entender y, de hecho, me va a rechazar. Sin embargo, si me muestro como él espera verme, se producirá el fenómeno del reconocimiento que hará la comunicación mucho más sencilla e incluso placentera. Quizá por eso sea tan difícil zafarnos de los estereotipos culturales. A fin de cuentas, parecen ser el único esperanto que verdaderamente funciona, aquella lingua franca que todos conocemos y manejamos. Hagamos un esfuerzo, al menos, para reconocerlos allá donde aparezcan.

día se interpretaban como una representación de La muerte del arzobispo de Québec a manos de los caníbales. Podría ser que estos otros cuadros de procedencia no española fuesen aportados por los propios organizadores de la bienal para engrosar la muestra de Goya del pabellón español, que de otro modo habría quedado algo escasa. 